\title{
Heat Transfer Characteristics of Submerged Two Phase Impinging Jets
}

\author{
Abdullah M. Kuraan, Victoria J. Centofanti, Yunus Ulus, Kyosung Choo \\ Mechanical and Industrial Engineering Department \\ Youngstown State University, Youngstown, OH 44555, United States \\ kchoo@ysu.edu
}

\section{Extended Abstract}

Impinging jets are widely applied in many engineering applications for the cooling, heating, and drying of surfaces due to higher rates of cooling, heating, and drying. Many researchers have investigated the heat transfer and fluid flow characteristics of single phase impinging jets in the past decades [1-3]. Recently, several researchers have examined heat transfer and fluid flow characteristics of single phase impinging jets at low nozzle-to-plate spacings and high nozzle-toplate spacings [4-5]. However, the understanding of heat transfer and fluid flow characteristics for submerged two-phase impinging jets in the wide range of nozzle-to-plate spacings is still limited.

The purpose of this study is to determine the effect of nozzle-to-plate spacing on heat transfer and fluid flow characteristics of submerged two-phase impinging jets on a flat surface using water and air as the working fluids. The effects of the nozzle-to-plate spacings $(H / d=0.08-30)$ on the Nusselt number and pressure are considered under a fixed water flow rate condition. Stagnation pressure of the submerged two-phase impinging jets was measured to understand a relationship with heat transfer characteristics. The nozzle-to-plate spacing was controlled with an x-y-z stage with a $10 \mu \mathrm{m}$ resolution, (Thorlabs, Inc, PT3A/M). Compressed air was supplied from a mass flow controller (Omega FMA5520A) having an accuracy level of $\pm 1 \%$ and a repeatability of $\pm 0.15 \%$. A grear pump (Micropump) was used to control water flow rate. A stainless steel foil was used as a heated surface, which was connected with a high voltage DC power supply (Agilent 6651A \#J03) in series with a shunt, rated 0-6 V and 0-60 A. Four K-type thermocouples of diameter 0.08 mm were used to measure temperature using OMEGA (OM-CP-QuadTemp2000) digital data acquisition system.

The results show that the Nusselt number and stagnation pressure are divided into three regions; Region I) jet deflection region $(H / d \leq 0.5)$, Region II) inertia dominant region $(0.5<H / d \leq 7)$, and Region III) buoyancy region $(7<H / d$ $\leq 30)$. In region I, the Nusselt number drastically increases with decreasing the nozzle-to-plate spacing due to the increase of the stagnation pressure with bubble collisions and bursts. In region II, the effect of the nozzle-to-plate spacing is negligible on the Nusselt number due to the inertia dominant effect in the potential core region with bubble collisions. In region III, the Nusselt number monotonically decrease with increasing the nozzle-to-plate spacing due to the decrease of bubble collisions on the surface by buoyancy force.

\section{References}

[1] B. W. Webb and C.-F. Ma, "Single-phase liquid jet impingement heat transfer," Adv. Heat Transfer, 26, pp. 105217, 1995.

[2] H. J. Park, D. H. Lee, S. W. Ahn, “An instrument for measuring heat flux from an isothermal surface," Int. J. Heat and Mass Transfer, vol. 37, pp. 179-18, 2012.

[3] D. Trainer, "Breakup length and liquid splatter characteristics of air-assisted water jets," Int. J. Heat and Mass Transfer, vol. 81, pp. 77-87, 2016.

[4] K. Choo, T.Y. Kang, S. J. Kim, “The effect of inclination on impinging jets at small nozzle-to-plate spacing," Int. J. Heat and Mass Transfer, vol. 55, pp. 3327-3334, 2012.

[5] K. Choo, B. K. Friedrich, A. W. Glaspell, K. A. Schilling, "The influence of nozzle-to-plate spacing on heat transfer and fluid flow of submerged jet impingement," Int. J. Heat and Mass Transfer, vol. 97, pp. 66-69, 2016. 